\title{
Carpal Fracture and COVID-19 Infection: Observation from Thailand
}

\author{
Beuy Joob ${ }^{1} \cdot$ Viroj Wiwanitkit ${ }^{2,3}$
}

Received: 20 March 2020 / Accepted: 9 April 2020 / Published online: 21 April 2020

(c) Indian Orthopaedics Association 2020

\section{Dear Editor,}

COVID-19 infection is the present global public health issue. From China, the disease has already reached more than 100 countries around the world [1]. The disease is a respiratory infection but sometimes it might have an atypical clinical history. Sometimes, the orthopedic problem might be a concurrent medical problem of the patient with COVID19. Here, the authors would like to share observations from Thailand, the second country where COVID-19 appeared after China [2]. At present (11th March 2020), there are 59 cases of COVID-19 in Thailand. Of these patients, there is an interesting patient who presented first with the complaint of an orthopedic problem. The patient is a 40 years old male patient who returned from Japan to Thailand on 27th February. This case fell down in Japan and had left carpal fracture and returned to Thailand for orthopedic surgery treatment. The surgery was successful but during post-operative hospitalization, the patient had fever and respiratory problem. The final diagnosis of COVID-19 by PCR test was on the 13th day of hospitalization. This patient is presently under respiratory care in the hospital. It shows that the orthopedic surgeon might be the first person who came into contact the patient with COVID-19. Although there is no clear information on interrelationship between orthopedic disorder and COVID-19 infection, it is necessary for orthopedic surgeon to know and recognize the new disease. During the COVID-19 in China, the infection in patients with fracture is also mentioned [3]. This report can support the importance of COVID-19 in the patient presenting with an orthopedic problem, fracture. The possible concurrence between an orthopedic problem and COVID-19 infection should not be forgotten. At present, the fracture

Beuy Joob

beuyjoob@hotmail.com

Sanitation 1 Medical Academic Center, Bangkok, Thailand

2 Dr DY Patil University, Pune, India

3 Hainan Medical University, Haikou, China patient might have pre-symptomatic COVID-19 and this might spread to the medical personnel or other patients. In post-operative management, COVID-19 might be a possible cause of post-operative fever. Some salient points on how the management differed from his regular patients are (a) special infection control in pre-, intra- and post-operative periods are necessary in known COVID-19 patients with fracture and early antiviral therapy is required since the prognosis of fracture patients with disease is usually poor [3] and (b) isolated respiratory care and antiviral therapy should be started as soon as possible in case the symptom first appears postoperatively.

\section{Compliance with Ethical Standards}

Conflict of interest The author(s) declare that they have no conflict of interest.

Ethical standard statement This work is not a study in human/animal but it is a retrospective public data analysis and it requires no ethical approval.

Informed consent Informed consent is not required.

\section{References}

1. Hsia, W. (2020). Emerging new coronavirus infection in Wuhan, China: Situation in early 2020. Case Study Case Report, 10, 8-9.

2. Yasri S, Wiwanitkit V. Editorial: Wuhan coronavirus outbreak and imported case. Advance Tropical Medicine and Public Health International 2019;9:1-2

3. Mi, B., Chen, L., Xiong, Y., Xue, H., Zhou, W., \& Liu, G. (2020). Characteristics and early prognosis of COVID-19 infection in fracture patients. Journal of Bone and Joint Surgery, American Volume. https://doi.org/10.2106/JBJS.20.00390.

Publisher's Note Springer Nature remains neutral with regard to jurisdictional claims in published maps and institutional affiliations. 